\title{
Face-selectivity in [4+2]-cycloadditions to novel polycyclic benzoquinones. Remarkable stereodirecting effects of a remote cyclopropane ring and an olefinic bond
}

\author{
Goverdhan Mehta, ${ }^{\mathrm{a}, *}$ Celine Le Droumaguet, ${ }^{\mathrm{a}}$ Kabirul Islam, ${ }^{\mathrm{a}}$ Anakuthil Anoop ${ }^{\mathrm{b}}$ and \\ Eluvathingal D. Jemmis ${ }^{\text {b,* }}$ \\ ${ }^{a}$ Department of Organic Chemistry, Indian Institute of Science, Bangalore 560 012, India \\ ${ }^{\mathrm{b}}$ School of Chemistry, University of Hyderabad, Hyderabad 500134, India
}

\begin{abstract}
Face selectivity in Diels-Alder reactions between specially crafted bicyclo[2.2.2]octane-fused benzoquinones, where the dienophilic moiety is imbedded in an isosteric environment, can be modulated by a remote olefinic bond and a cyclopropane ring. Quantum mechanical calculations while reproducing the observed diastereoselectivities at the TS level indicate the involvement of ground state orbital effects.
\end{abstract}

The $\left[\pi 4_{\mathrm{s}}+\pi 2_{\mathrm{s}}\right]$-cycloaddition (the Diels-Alder reaction), ${ }^{1 a}$ resulting in the formation of two $\mathrm{C}-\mathrm{C}$ bonds and the generation of up to four stereogenic centers in a single laboratory operation, is among the most versatile reactions in the armamentarium of synthetic chemists and has been widely exploited. ${ }^{1}$ The stereo-, regio- and topographical (endo versus exo) control in these cycloadditions has sound predictability and further enhances its synthetic appeal. ${ }^{1 \mathrm{~d}}$ However, a more subtle issue of diastereoselectivity in [4+2]-cycloadditions arises through $\pi$-face selectivity when either of the reacting partners viz. the diene or the dienophile is facially dissymmetric. ${ }^{2}$ Studies involving acyclic 1,3dienes and various dienophiles have revealed that $\pi$ face selection is generally dominated by steric and conformational factors and the role of electronic effects, if any, often become masked. Recent efforts have focused on investigating substrates wherein the 1,3-diene moiety is embedded into a polycyclic frame to minimize conformational and steric effects and these studies have indicated the importance of orbital mixing/ tilting, secondary orbital interactions, hyperconjugative effects and electrostatic effects as additional factors in

\footnotetext{
* Corresponding authors. E-mail: gm@orgchem.iisc.ernet.in; jemmis @uohyd.ernet.in
}

determining diastereoselectivity. ${ }^{3}$ A complementary approach wherein a dienophile is embedded in a dissymmetric environment has received very limited attention. ${ }^{4}$ Sometime ago, we investigated [4+2]-cycloadditions in norbornyl- and norbornenyl-fused benzoquinones 1-2 and found that the face-selectivities were largely determined by steric considerations. ${ }^{4 b, c}$ These findings were complicated by the fact that the two $\pi$-faces in $\mathbf{1}$ and $\mathbf{2}$ are sterically differentiated by the presence of the 'methano' and 'ethano' or 'etheno' subunits, making it difficult to glean the effect of subtle electronic factors. This led us to craft new systems in which the dienophile is in a nearly isosteric environment, such that diastereoselectivity is not manifested through steric factors and facial discrimination can be induced through electronic modification at a distal position. With this backdrop, we identified the bicyclo[2.2.2] octane-fused benzoquinone system 3 for the present study where facial discrimination can be induced through modification of one of the ethano bridges. Based on this premise, [4+2]-cycloaddition of novel quinones 4-8, with minimal steric differentiation of the $\pi$-faces and only endo-ring annulation, with cyclopentadiene, has been studied experimentally and computationally. We have encountered rare examples of the profound effect of remote electronic perturbations on $\pi$-face selectivity and these findings constitute the subject of this communication. 


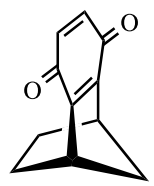

1

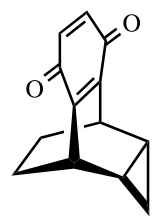

5

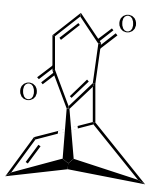

2

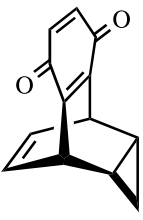

6

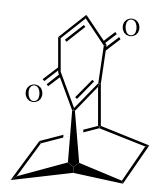

3

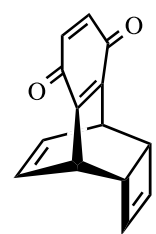

7

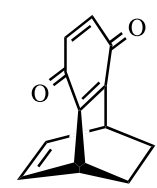

4

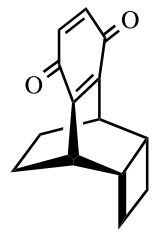

8 yields (Scheme 1). In each case, the adducts through endo-addition to both the $\pi$-faces of the distal quinone double bond were isolated (silica gel column chromatography) and the ratios shown in Scheme 1 were obtained through ${ }^{1} \mathrm{H}$ NMR integration of the well separated relevant protons. ${ }^{7}$ The endo-stereochemical disposition of the adducts 9-18 was secured through their intramolecular [2+2]-photocyclization to the corresponding polycyclic caged compounds 19-28, respectively, as displayed in Scheme $2 .{ }^{7}$ The complete stereostructures of the diastereomeric adducts 9-18 were unambiguously deduced through complementary ${ }^{1} \mathrm{H}$ and ${ }^{13} \mathrm{C}$ NMR data, X-ray crystal structures ${ }^{8}$ of $\mathbf{1 0}$, 13, 22, 26 and chemical correlation.

The observed facial-selectivities in the cycloaddition of cyclopentadiene to benzoquinones $\mathbf{4 - 8}$ are quite remarkable. For example, dissymmetrization of the two $\pi$-faces in 3 through the incorporation of a remote double bond as in $\mathbf{4}$ leads to a significant 75:25 (9:10) preference for the face syn to the etheno bridge. Similarly, dissymmetrization in $\mathbf{3}$ through endo fusion of a three- membered ring, with practically no steric facial bias, results in 68:32 (12:11) selectivity from the cyclopropane bearing face, Scheme 1 . The strong $\pi$-donor by the appropriate bond angles. All the annulated benzoquinones $\mathbf{4} \mathbf{8}$ reacted smoothly with cyclopentadiene, under ambient conditions within minutes, to furnish the 1:1 endo-adducts $\mathbf{9 - 1 8}$ in near-quantitative
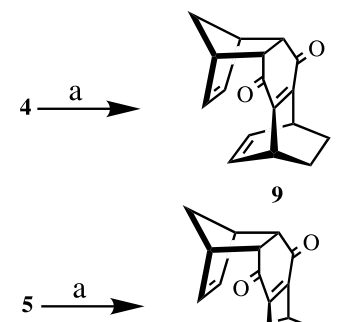

9

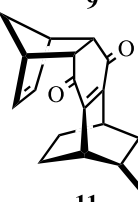

11
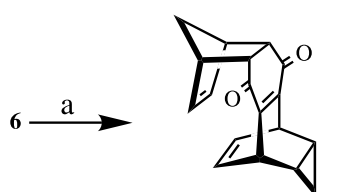

13
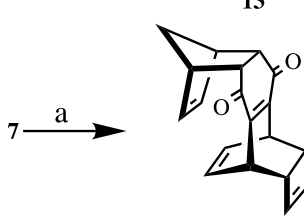

15
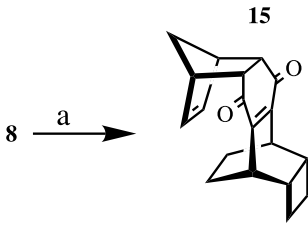

17

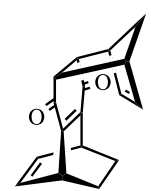

$75: 25$

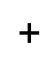

$32: 68$

$+$

$67: 33$

$+$

$71: 29$

$+$

$\mathbf{5 0}: \mathbf{5 0}$

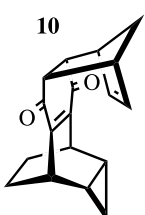

12

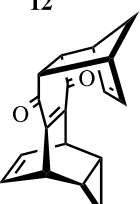

14

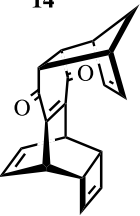

16

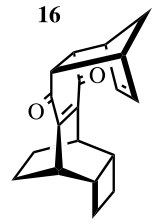

18
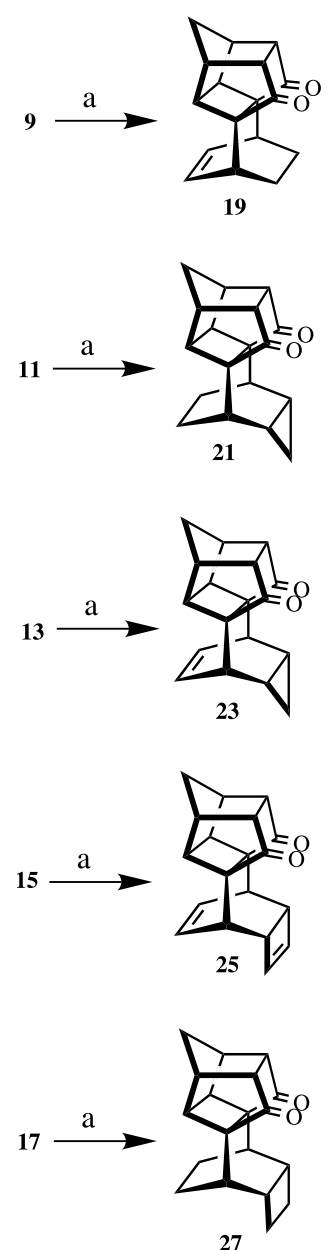

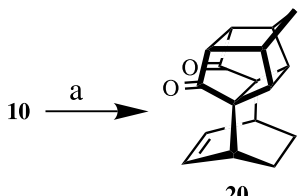

20
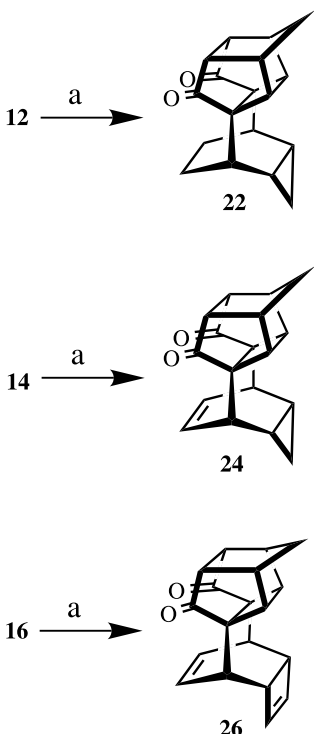

26

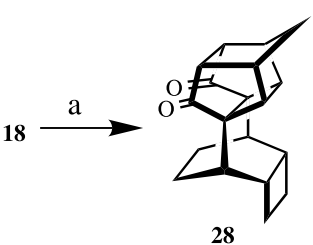

Scheme 1. Reagents and conditions: (a) cyclopentadiene, benzene, r.t., 15-30 $\mathrm{min}$, quantitative.
Scheme 2. Reagents and conditions: (a) $450 \mathrm{~W}, \mathrm{CDCl}_{3}$, quantitative. 
Table 1. Experimental ratios, relative energies (RE), R.E. (ZPE corrected), activation energies (kcal/mole), activation energies (ZPE corrected), free energy of activation, ratio of rate constants of compounds 9-18

\begin{tabular}{|c|c|c|c|c|c|c|c|}
\hline Comp No. & $\%$ & R.E. & $\mathrm{RE}+\mathrm{ZPE}$ & $\Delta E^{*}$ & $\Delta E^{\ddagger}+\mathrm{ZPE}$ & $\Delta G^{\ddagger}$ & $k_{1} / \mathrm{k}_{2}$ \\
\hline 9 & 75 & 0.2 & 0.2 & 14.5 & 16.2 & 29.02 & \\
\hline 10 & 25 & 0.0 & 0.0 & 15.3 & 17.0 & 30.08 & 6.015 \\
\hline 11 & 32 & 0.0 & 0.0 & 15.2 & 17.0 & 30.07 & \\
\hline 12 & 68 & 0.2 & 0.2 & 14.9 & 16.7 & 29.69 & 0.486 \\
\hline 13 & 67 & 0.1 & 0.1 & 14.5 & 16.2 & 29.08 & \\
\hline 14 & 33 & 0.0 & 0.0 & 15.1 & 16.9 & 29.91 & 4.047 \\
\hline 15 & 71 & 0.1 & 0.1 & 14.4 & 16.1 & 28.99 & \\
\hline 16 & 29 & 0.0 & 0.0 & 15.0 & 16.9 & 30.03 & 5.858 \\
\hline 17 & 50 & 0.0 & 0.0 & 15.1 & 16.8 & 29.93 & \\
\hline 18 & 50 & 0.0 & 0.0 & 15.1 & 16.9 & 30.21 & 1.613 \\
\hline
\end{tabular}

$k$ calculated from the Arrhenius equation, $k=k_{\mathrm{b}} T / h\left[\mathrm{e}\left(-\Delta G^{\ddagger} / \mathrm{RT}\right)\right]$.

abilities of the cyclopropyl group through its high-lying Walsh orbital, similar to that of a double bond are well documented. ${ }^{9}$ The involvement of the cyclopropane orbitals in determining the diastereoselectivity in the present case becomes apparent on comparing the results with the cyclobutane fused quinone $\mathbf{8}$ in which no facial preference $(\mathbf{1 7 : 1 8}, 50: 50)$ is observed. Thus, both the double bond and the cyclopropane ring exert comparable long-range electronic effects on facial-selectivity. When both the $\pi$-faces of $\mathbf{3}$ are perturbed by pitching the double bond and the cyclopropane ring antagonistically as in quinone 6, there is a clear 67:33 (13:14) preference for the etheno face. Interestingly, in this case the contribution of the double bond $\pi$-orbitals humbles the cyclopropane Walsh orbitals. This dominating effect of the olefinic bond in promoting syn selectivity is also seen in the cyclobutene-fused quinone 7 which adds cyclopentadiene to furnish $\mathbf{1 5}$ as the major product (15:16, 71:29), Scheme 1.

The significant $\pi$-face diastereoselectivities described above, prompted us to examine the thermodynamic versus kinetic control of these reactions computationally. Accordingly, the structures of quinones $\mathbf{4} \mathbf{8}$, their cyclopentadiene addition products $9-\mathbf{1 8}$ and the ten transition structures TS9-TS18 leading to them were optimized using Density Functional Theory at the B3LYP/6-31G* level. ${ }^{10}$ All the stationary points were characterized as ground states or transition states by calculating the number of imaginary vibrational frequencies. The energy differences between each of the diastereomeric pairs is small and not in tune with the observed product distribution (RE in Table 1), ruling out thermodynamic control and product stability as the determinants of face-selectivity. We then turned to transition states. These were characterized at the same level as having one imaginary vibrational frequency. There was nothing exceptional in the geometrical parameters but the activation energies calculated as the difference in energies between the reactant and the transition state showed a remarkable correlation with the experimentally observed product ratios which were not changed by the inclusion of the ZPE corrections. The free energies of activation as well as the ratio of rate constants calculated for room temperature also reflected a similar trend (Table 1).

While it is not easy to separate the steric and orbital effects within such small magnitudes, the obvious change in the symmetry of the system prompted us to probe the perturbation of the $\pi$ MOs of the parent quinone 3 as a consequence of the introduction of the olefinic bond and endo-ring annulation. The p-orbitals of the HOMO at the reaction center constituted a pure $\pi$ bond; the mixing of s orbitals was zero by symmetry in 3. However, a distal $\pi$ orbital as in $\mathbf{4}$ was found to interact with the $\pi$ MOs at the reaction center leading to $\mathrm{sp}$ mixing and making the syn face predisposed towards a better overlap with the incoming diene and reducing the TS energy, albeit by a small magnitude. The differing size of the lobes of the $\pi$ orbitals on the two faces of quinones $\mathbf{4 - 8}$ suggests that the diastereoselectivities observed here has a contribution from orbital effect (Scheme 3). ${ }^{3 a}$

In conclusion, we have studied $\pi$-facial selectivities in $[4+2]$ cycloadditions to novel bicyclo[2.2.2]octane annulated quinones and observed a remarkable syn-directing effect of a remote double bond and a cyclopropane

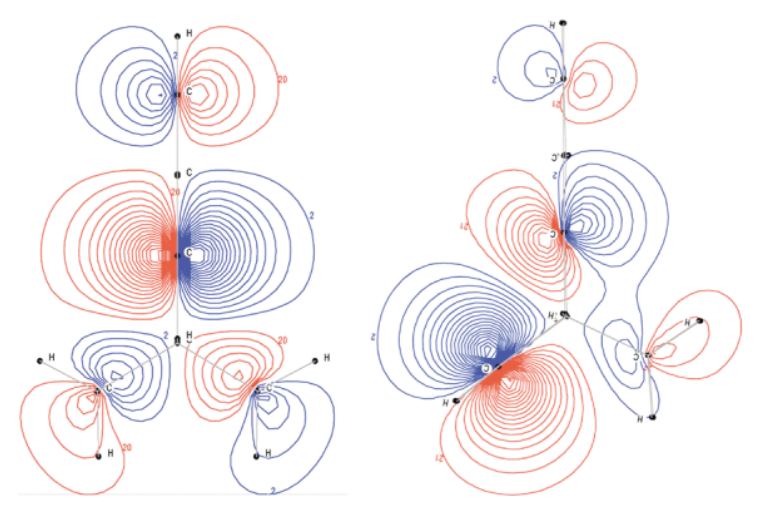

Scheme 3. Highest occupied $\pi$-MOs of 3 and $\mathbf{4}$, showing the dissymmetric reaction center. 
ring. Computational studies demonstrate an excellent convergence between transition state energetics and experimental results and point to subtle ground state orbital effects as the main causative factors for the $\pi$-face selection.

\section{Acknowledgements}

K.I. thanks CSIR, India for the award of a research fellowship. C.L.D. was a visiting student from the University of Rennes, France. X-Ray data was collected at the National CCD facility at IISc.

\section{References}

1. (a) Diels, O.; Alder, K. Justus Liebigs. Ann. Chem. 1928, 460, 98; (b) Carruthers, W. Cycloaddition Reactions in Organic Synthesis; Pergamon: Oxford, 1990; (c) Fallis, A. G. Acc. Chem. Res. 1999, 32, 464; (d) Nicolaou, K. C.; Snyder, S. A.; Montagnon, T.; Vassilikogiannakis, G. Angew. Chem. Int. Ed. 2002, 41, 1668.

2. Selected references: (a) Angell, E. C.; Fringuelli, F.; Pizzo, P.; Tatichhi, A.; Wenkert, E. J. Org. Chem. 1986, 51, 2642; (b) Brown, F. K.; Houk, K. N.; Burnell, D. J.; Valenta, Z. J. Org. Chem. 1987, 52, 3050; (c) Kahn, S. D.; Hehre, W. J. J. Am. Chem. Soc. 1987, 109, 663; (d) Macaulay, J. B.; Fallis, A. G. J. Am. Chem. Soc. 1990, 112, 1136; (e) Fessner, W. D.; Grund, C.; Prinzbach, H. Tetrahedron Lett. 1991, 32, 5935; (f) Mehta, G.; Padma, S.; Reddy, H. K.; Nethaji, M. J. Chem. Soc., Perkin Trans. 1 1994, 2049; (g) Mehta, G.; Uma, R. Tetrahedron Lett. 1995, 36, 4873; (h) Wellman, M. A.; Burry, L. C.; Letourneau, J. E.; Bridson, J. N.; Miller, D. O.; Burnell, D. J. J. Org. Chem. 1997, 62, 939; (i) Mehta, G.; Uma, R. J. Org. Chem. 2000, 65, 1685.

3. Reviews: (a) Ohwada, T. Chem. Rev. 1999, 99, 1337; (b) Coxon, J. M.; Froese, R. D. G.; Ganguli, B.; Marchand, A. Synlett 1999, 1681; (c) Mehta, G.; Uma, R. Acc. Chem. Res. 2000, 33, 278; (d) Marchand, A., Coxon, J. M. Acc. Chem. Res. 2002, 35, 271.

4. (a) Edman, J. R.; Simmons, H. E. J. Org. Chem. 1968, 33, 3808; (b) Mehta, G.; Padma, S.; Pattabhi, V.; Pramanik, A.; Chandrasekhar, J. J. Am. Chem. Soc. 1990, 112, 2942; (c) Mehta, G.; Reddy, H. K.; Reddy, D. S. K. Tetrahedron Lett. 1991, 32, 6399; (d) Mehta, G.; Reddy, H. K. Angew. Chem. Int. Ed. 1993, 32, 1160; (e) Carreno, M. Chem. Rev. 1995, 95, 1717; (f) Okamoto, I.; Ohwada, T.; Schdo, K. J. Org. Chem. 1996, 61, 3155 .

5. Bicyclo[2.2.2]annulated benzoquinones $\mathbf{4 8}$ were prepared from the Diels-Alder adducts of benzoquinone with 1,3-cyclohexadiene, 1,3,5-cycloheptatriene and cyclooctatetraene, respectively, and further transformations patterned along the procedure described in: (a) Cookson, R. C.; Hill, R. R.; Hudec, J. J. Chem. Soc. 1964, 3043; (b) Mehta, G.; Padma, S. J. Am. Chem. Soc. 1987, 109, 7230. Details of the syntheses of $\mathbf{4 - 8}$ will be described in the full paper.
6. The X-ray crystal data for annulated quinones $\mathbf{5}$ and $\mathbf{7}$ will be reported elsewhere.

7. All new compounds reported here were fully characterized on the basis of spectroscopic (IR, ${ }^{1} \mathrm{H}$ and ${ }^{13} \mathrm{C}$ NMR, Mass) data. ${ }^{13} \mathrm{C}$ NMR $\left(\mathrm{CDCl}_{3}\right)$ data for new compounds. 9: ${ }^{13} \mathrm{C}$ NMR (75 MHz): $\delta 195.31$ (CO), 154.61 (quat), $134.54(\mathrm{CH}), 133.95(\mathrm{CH}), 49.46(\mathrm{CH})$, $49.32\left(\mathrm{CH}_{2}\right), 49.13(\mathrm{CH}), 34.00(\mathrm{CH}), 24.34\left(\mathrm{CH}_{2}\right) ; \mathbf{1 0}$ : ${ }^{13} \mathrm{C}$ NMR (75 MHz): $\delta 195.17$ (CO), 154.15 (quat), $134.77(\mathrm{CH}), 133.57(\mathrm{CH}), 49.38(\mathrm{CH}), 48.72\left(\mathrm{CH}_{2}\right)$, $48.69(\mathrm{CH}), 33.98(\mathrm{CH}), 24.49\left(\mathrm{CH}_{2}\right) ; 11:{ }^{13} \mathrm{C}$ NMR $(75$ $\mathrm{MHz}$ ): $\delta 196.52$ (CO), 158.83 (quat), $134.96(\mathrm{CH}), 49.82$ $(\mathrm{CH}), \quad 49.42\left(\mathrm{CH}_{2}\right), 49.29(\mathrm{CH}), 28.00(\mathrm{CH}), 22.89$ $\left(\mathrm{CH}_{2}\right), 21.23(\mathrm{CH}), 14.66\left(\mathrm{CH}_{2}\right) ; 12:{ }^{13} \mathrm{C}$ NMR $(75$ $\mathrm{MHz}): \delta 196.34$ (CO), 158.57 (quat), $134.69(\mathrm{CH}), 49.36$ $(\mathrm{CH}), 49.20\left(\mathrm{CH}_{2}\right), 49.17(\mathrm{CH}), 27.58(\mathrm{CH}), 22.52$ $\left(\mathrm{CH}_{2}\right), 20.77(\mathrm{CH}), 14.18\left(\mathrm{CH}_{2}\right) ; 13:{ }^{13} \mathrm{C}$ NMR $(75$ MHz): $\delta$ 195.65 (CO), 160.25 (quat), $134.57(\mathrm{CH})$, $130.26(\mathrm{CH}), 49.56(\mathrm{CH}), 49.17\left(\mathrm{CH}_{2}\right), 48.87(\mathrm{CH})$, $35.63(\mathrm{CH}), 17.50(\mathrm{CH}), 15.72\left(\mathrm{CH}_{2}\right) ; \mathbf{1 4}:{ }^{13} \mathrm{C}$ NMR $(75$ $\mathrm{MHz}): \delta 195.54$ (CO), 159.87 (quat), $134.74(\mathrm{CH})$, $129.87(\mathrm{CH}), 49.53(\mathrm{CH}), 48.89\left(\mathrm{CH}_{2}\right), 48.82(\mathrm{CH})$, $35.71(\mathrm{CH}), 17.93(\mathrm{CH}), 16.33\left(\mathrm{CH}_{2}\right) ; 15:{ }^{13} \mathrm{C}$ NMR $(75$ $\mathrm{MHz}$ ): $\delta 195.96$ (CO), 155.51 (quat), $138.49(\mathrm{CH})$, $134.61(\mathrm{CH}), 130.28(\mathrm{CH}), 49.66(\mathrm{CH}), 49.30\left(\mathrm{CH}_{2}\right)$, $49.10(\mathrm{CH}), 44.08(\mathrm{CH}), 38.26(\mathrm{CH}) ; 16:{ }^{13} \mathrm{C}$ NMR $(75$ $\mathrm{MHz}): \delta 195.83$ (CO), 155.10 (quat), $138.47(\mathrm{CH})$, $134.85(\mathrm{CH}), 129.90(\mathrm{CH}), 49.61(\mathrm{CH}), 48.79\left(\mathrm{CH}_{2}\right)$, $48.77(\mathrm{CH}), 44.30(\mathrm{CH}), 38.28(\mathrm{CH}) ; 17$ and $18:{ }^{13} \mathrm{C}$ NMR (75 MHz): $\delta 195.83$ (CO, 2C), 154.25 (quat 2C), $134.66(\mathrm{CH}), 134.62(\mathrm{CH}), 49.27(\mathrm{CH}), 49.12(\mathrm{CH})$, $49.00\left(\mathrm{CH}_{2}\right), 48.85\left(\mathrm{CH}_{2}\right), 48.80(\mathrm{CH}), 48.78(\mathrm{CH}), 34.23$ $(\mathrm{CH}), 34.02(\mathrm{CH}), 30.22(\mathrm{CH}, 2 \mathrm{C}), 19.49\left(\mathrm{CH}_{2}\right), 19.28$ $\left(\mathrm{CH}_{2}\right), 17.52\left(\mathrm{CH}_{2}\right), 17.40\left(\mathrm{CH}_{2}\right)$.

8. Crystal data: X-ray data were collected at $293 \mathrm{~K}$ on a SMART CCD-BRUKER diffractometer with graphite monochromated $\mathrm{MoK} \alpha$ radiation $(\lambda=0.7103 \AA)$. The structures were solved by direct methods (SIR92). Refinement was by full-matrix least-squares procedures on F2 using SHELXL-97. All the CIF files have been submitted to the Cambridge Crystallographic Data Centre and assigned the corresponding dipository numbers. Compound 10: $\mathrm{C}_{17} \mathrm{H}_{16} \mathrm{O}_{2} \mathrm{MW}=252$, Crystal system: monoclinic, space group: $P 2(1) / n$, cell parameters: $a=6.287$ (1) $\AA, b=11.588$ (3) $\AA, c=17.658$ (4) $\AA, \beta=96.847$ (4) ${ }^{\circ}$, $V=1277.47$ (6) $\AA^{3}, Z=4, D_{\mathrm{c}}=1.312 \mathrm{~g} \mathrm{~cm}^{-3}, F(000)=$ 536.0, $\mu=0.08 \mathrm{~mm}^{-1}$. $R_{1}=0.0842$ for $1873 F_{\mathrm{o}}>4 \sigma\left(F_{\mathrm{o}}\right)$ and 0.1216 for all 2560 data. $\mathrm{GOF}=1.247$, Restrained $\mathrm{GOF}=1.247$ for all data, CCDC 203633. Compound 13: $\mathrm{C}_{18} \mathrm{H}_{16} \mathrm{O}_{2}, \mathrm{MW}=264$, Crystal system: monoclinic, space group: $P 2(1) / c$, cell parameters: $a=6.3737$ (9) $\AA, b=$ 21.906 (3) $\AA, c=9.636$ (1) $\AA, \beta=101.360$ (1),$V=$ $1319.12 \AA^{3}, Z=4, D_{\mathrm{c}}=1.331 \mathrm{~g} \mathrm{~cm}^{-3}, F(000)=560.0$, $\mu=0.09 \mathrm{~mm}^{-1} . \quad R_{1}=0.0417$ for $1637 \quad F_{\mathrm{o}}>4 \sigma\left(F_{\mathrm{o}}\right)$ and 0.0657 for all 2250 data. $\mathrm{GOF}=1.011$, Restrained $\mathrm{GOF}=1.011$ for all data, CCDC 203634. Compound 22: $\mathrm{C}_{18} \mathrm{H}_{18} \mathrm{O}_{2}, \mathrm{MW}=266$, Crystal system: monoclinic, space group: Cc, cell parameters: $a=46.308$ (7) $\AA, b=6.483$ (1) $\AA, c=28.794$ (4) $\AA, \beta=116.277(3)^{\circ}, V=7751.57 \AA^{3}$, $Z=24, \quad D_{\mathrm{c}}=1.246 \mathrm{~g} \mathrm{~cm}^{-3}, \quad F(000)=3120.0, \quad \mu=0.08$ $\mathrm{mm}^{-1} . R_{1}=0.0676$ for $6586 F_{\mathrm{o}}>4 \sigma\left(F_{\mathrm{o}}\right)$ and 0.1736 for all 15747 data. $\mathrm{GOF}=0.876$, Restrained $\mathrm{GOF}=0.876$ for 


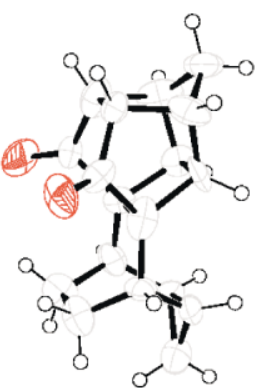

ORTEP of compound 22

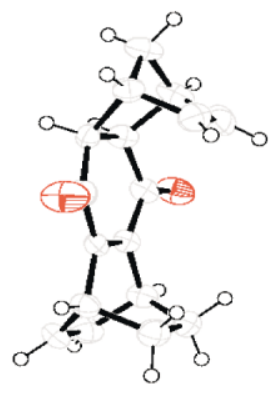

ORTEP of compound $\mathbf{1 0}$

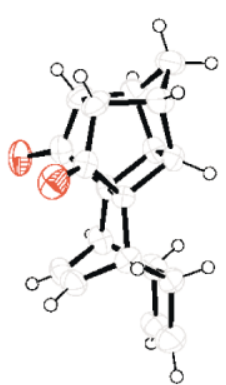

ORTEP of compound $\mathbf{2 6}$

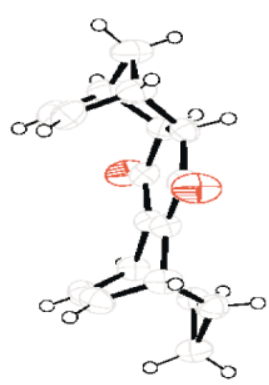

ORTEP of compound $\mathbf{1 3}$ all data, CCDC 203635. Compound 26: $\mathrm{C}_{19} \mathrm{H}_{16} \mathrm{O}_{2}, \mathrm{MW}=$ 276, Crystal system: monoclinic, space group: $P 2(1) / n$, cell parameters: $a=6.380$ (1) $\AA, b=18.104$ (2) $\AA, c=$ 11.723 (1) $\AA, \beta=105.417(3)^{\circ}, V=1305.46 \AA^{3}, Z=4$, $D_{\mathrm{c}}=1.406 \mathrm{~g} \mathrm{~cm}^{-3}, F(000)=584.0, \mu=0.09 \mathrm{~mm}^{-1} . R_{1}=$ 0.0776 for $1845 F_{\mathrm{o}}>4 \sigma\left(F_{\mathrm{o}}\right)$ and 0.1237 for all 2237 data. $\mathrm{GOF}=1.198$, Restrained $\mathrm{GOF}=1.198$ for all data, CCDC 203636. ORTEP drawings of compounds 10, 13, 22 and 26 with 50\% ellipsoidal probability are shown below.

9. Hoffmann, R.; Davidson, R. B. J. Am. Chem. Soc. 1971, 93, 5699.

10. Frisch, M. J.; Trucks, G. W.; Schelegel, H. B.; Gill, P. M. W.; Johnson, B. G.; Robb, M. A.; Cheeseman, J. R.; Keith, T.; Peterson, G. A.; Montgomery, J. A.; Raghavachari, K.; Al-Laham, M. A.; Zakrzewski, V. G.; Ortiz, J. V.; Foresman, J. B.; Cioslowsky, J.; Stefenov, B. B.; Nanayakkara, A.; Challacombe, M.; Peng, C. Y.; Ayala, P. Y.; Chen, W.; Wong, M. W.; Andres, J. L.; Replogle, E. S.; Gomberts, R.; Martin, R. L.; Fox, D. J.; Binkley, J. S.; Defrees, D. J.; Baker, J.; Stewart, J. P.; Head-Gordon, M.; Gonzalez, C.; Pople, J. A. Gaussian 94, Revision D.1; Gaussian, Inc: Pittsburg, PA, 1995. 